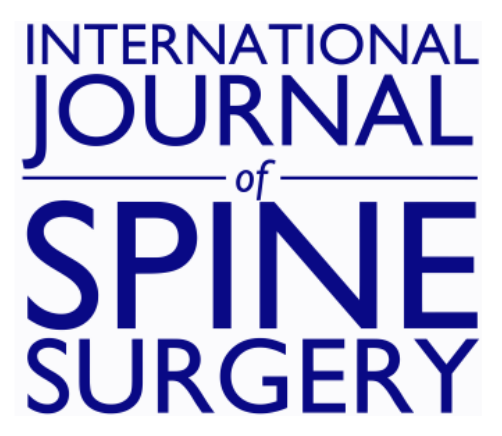

\title{
Uniportal Endoscopic Interlaminar Decompression in Lumbar Spinal Stenosis: A Comprehensive Review
}

Kuang-Yuan Goh, Jui-Chen Hsu, Ching-Yu Lee, Tsung-Jen Huang, Chien-Min Chen and Meng-Huang Wu

Int J Spine Surg 2021, 15 (suppl 3) S54-S64

doi: https://doi.org/10.14444/8164

http://ijssurgery.com/content/15/suppl_3/S54

This information is current as of April 26, 2023.

Email Alerts Receive free email-alerts when new articles cite this article. Sign up at:

http://ijssurgery.com/alerts

The International Journal of Spine Surgery

2397 Waterbury Circle, Suite 1,

Aurora, IL 60504, Phone: +1-630-375-1432 


\title{
Uniportal Endoscopic Interlaminar Decompression in Lumbar Spinal Stenosis: A Comprehensive Review
}

\author{
KUANG-YUAN GOH, MD ${ }^{1}$; JUI-CHEN HSU, MD ${ }^{1}$; CHING-YU LEE, MD, PHD ${ }^{2,3}$; TSUNG-JEN HUANG, MD, PHD ${ }^{2,3}$; \\ CHIEN-MIN CHEN, MD, PHD ${ }^{4,5,6}$; AND MENG-HUANG WU ${ }^{2,3}$ \\ ${ }^{I}$ Department of Medical Education, Taipei Medical University Hospital, Taipei, Taiwan; ${ }^{2}$ Department of Orthopedics, Taipei Medical University Hospital, Taipei, \\ Taiwan; ${ }^{3}$ Department of Orthopaedics, School of Medicine, College of Medicine, Taipei Medical University, Taipei, Taiwan; ${ }^{4}$ Division of Neurosurgery, Department of \\ Surgery, Changhua Christian Hospital, Changhua, Taiwan; ${ }^{5}$ School of Medicine, Kaohsiung Medical University, Kaohsiung, Taiwan; ${ }^{6}$ College of Nursing and Health \\ Sciences, Dayeh University, Dacun, Taiwan
}

\begin{abstract}
Background: From the 1990s, there has been growth in the literature demonstrating the feasibility of minimally invasive approaches for treating variety lumbar spinal disorders. There is still much work to be done in overcoming the technical challenges and explicate relative advantages of endoscopic techniques in lumbar spine surgery. In this comprehensive literature review, we discuss the history, indications, contraindications, surgical techniques, learning curves, technical tips, adverse events, and examine peer-reviewed studies addressing uniportal endoscopic interlaminar decompression in lumbar spinal surgery.

Methods: This literature review was conducted with keywords "endoscopic," "minimally invasive," "uniportal endoscopic decompression," "interlaminar decompression," and "lumbar spinal surgery" using PubMed, Embase, ClinicalKey, and Google Scholar.

Results: Review of 423 patients who underwent uniportal endoscopic interlaminar lumbar decompression showed satisfying results with $82 \%$ of patients no longer having leg pain, and $13 \%$ of patients having only occasional pain, with no significant operation-related deterioration in leg or back pain. To compare the outcomes between endoscopic and microscopic technique, a comparative review of 192 lumbar lateral recess stenosis patients demonstrated the uniportal endoscopic group had $29 \%$ shorter operation duration, $1.2 \%$ fewer perioperative complications, and significantly reduced postoperative pain (visual analog scale) over 5 days, and reduced use of pain medications. Multiple retrospective studies echoed the outcomes of endoscopic decompression surgery, showed shorter hospitalization time, lower mean dural expansion, lower increment of horizontal displacement measured, and less elevated levels of postoperative serum CPK (creatine phosphokinase) and CRP (creactive protein). Lastly, a systematic review and meta-analysis that enrolled 994 patients found that patients who received the full-endoscopic decompression technique showed statistically lower levels of back pain and leg pain and a $40 \%$ lower chance of having complications compared with those receiving microscopic decompression in lumbar stenosis.

Conclusions: Based on our literature review, there are multiple positive outcomes with endoscopic interlaminar lumbar decompression, which reduces operation duration, perioperative complications, and better postoperative outcomes. However, the technical challenge highlights the importance of further training and innovation in this rapidly evolving field.

Special Issue
\end{abstract}

\section{INTRODUCTION}

Degenerative lumbar spinal stenosis (DLSS) is an emerging disease affecting patients older than 65 years, and the number of patients affected are estimated to increase up to $59 \%$ and influences 64 million elders in 2025. Neurogenic claudication is the most common symptomatic sign of DLSS due to compression by the surrounding structures to the thecal sac, including hypertrophic ligamentum flavum (LF), enlarged osteoarthritic facet joints, and degenerative discs. Neurogenic claudication will deteriorate the quality of life in the elderly and is considered a surgical indication. ${ }^{1}$

Surgical treatments are performed in patients with neurogenic claudication with moderate or severe radicular pain in whom conservative treatments failed. $^{2-4}$ Thus, decompressive surgery usually effectively improves the symptoms and quality of life of these patients.

\section{History of Uniportal Endoscopic Lumbar Decom- pression Technique}

Minimally invasive spine surgery has continued to evolve over the past 3 decades, gaining popularity among spine surgeons due to its advantages over traditional open surgery. Endoscopic spine surgery has evolved over time to be in sync with the increasing number of patients in DLSS. ${ }^{5}$ Open interlaminar access was first mentioned in the early 20 th century and gradually progressed to the minimally invasive approach 
that has been used since the early $1970 s .{ }^{6-8}$ In the late 1970s, microscopy was introduced to the interlaminar access in decompression surgery. ${ }^{9,10}$ Parviz Kambin in 1973 and Hijikata in 1975 were developing percutaneous nucleotomy that led to the rapid development of endoscopy. ${ }^{11}$ Endoscopic spine surgery started slowly with full-endoscopic transforaminal procedures, which allowed access to the spinal canal without causing major open wounds. ${ }^{6,12-14}$ However, the procedure encountered difficulties in working mobility owing to the unfamiliar anatomy of a neural foramen. In addition, the high iliac crest limits access to the spinal canal through the transforaminal surgical route in the lower lumbar levels, limiting the efficacy of the transforaminal approach. Rapid developments in fullendoscopic interlaminar procedure were developed in the late 1990s.. ${ }^{15,16}$ The transforaminal endoscopic technique was initially used to treat disc herniation and later expanded to various diseases, such as central and lateral recess canal stenosis and foraminal stenosis. Herniated disc of the L5-S1 level was efficiently accessed using the interlaminar endoscopic approach, overcoming the anatomic barrier of the high iliac crest in the transforaminal endoscopic approach. ${ }^{17,18}$

The lumbar endoscopic technique of unilateral laminotomy with bilateral decompression (LEULBD) has the advantage of preserving spinous processes and ligaments to prevent postoperative segment instability. Due to the minimization of collateral damage, patients will recover earlier and have a shorter duration of hospitalization. In addition, patients can avoid the curve progression associated with traditional open techniques. Studies have reported that LE-ULBD for lumbar stenosis achieves similar results in improving neurogenic claudication and neurological deficits and has fewer complications compared with open laminectomy. ${ }^{19-21}$ A large retrospective study in $2018^{22}$ showed that full-endoscopic decompression was significantly superior in terms of surgical site infections, postoperative pain, and total complication rate. Clinical outcomes from several studies also showed less blood loss during operation, lower adverse effects, shorter hospitalization duration, and quicker improvements in Oswestry Disability Index (ODI scores); all of these results suggest that LE-ULBD would not be inferior to traditional open spine surgery. ${ }^{17-20}$

In this article, we aim to focus on evaluating and suggesting the potential of full-endoscopic lumbar decompression techniques by conducting a comprehensive review.

\section{INDICATIONS}

Due to the epidemiology of elderly patients in lumbar central canal stenosis, open decompression technique may cause many complications, which may lead to longer hospitalization and greater invasion, resulting in a larger surgical wound. In open fenestration, lumbosacral fascia is dissected and paraspinal muscle of the bilateral sides are stripped, damaging the posterior structure, which provides stability, and leads to poor outcomes, such as muscle damage, large incisions, and postoperative instability. ${ }^{23}$ Therefore, restricting muscle injury and keeping the bone resection range as minimal as possible are important for elderly patients to avoid postoperative hematoma. As mentioned above, LE-ULBD using a narrow outer tube with large working space would be more suitable in these operations.

A thorough spine workup can provide surgeons with indications of using endoscopic approaches to the lumbar spine. By obtaining adequate imaging studies, such as radiography, computed tomography, and magnetic resonance imaging, no more than 3 months before the operation, the surgeon can be informed not only of the type of spinal stenosis or disc herniation but also of the possibility of endoscopic access. ${ }^{18,24}$ Combined with neurogenic claudication with or without radiculopathy and unsuccessful conservative treatments for more than 3 months, endoscopic approaches could be established for indicated interventions.

\section{CONTRAINDICATIONS}

When performing endoscopic spine surgery, the main purpose is to reduce iatrogenic complications and maintain the stability and mobility of proper segments. However, due to the relatively steep learning curve of endoscopic decompression, the skill or proficiency of a spine surgeon may influence surgical outcomes. Hence, there are some general contraindications for endoscopy in lumbar spine surgery, including severe stenosis, severe fibrotic tissue adhesion, calcified disc, painless weakness, and cauda equina syndrome. ${ }^{23}$ Considerable incomplete decompressions or adverse effects occurred when applying the endoscopic procedures to patients beyond the indications for such procedures. Therefore, appropriate patient selection should be strictly implemented for a successful and safe outcome. However, as research and technical developments continue to advance, these general contraindications may be overcome in the near future. 


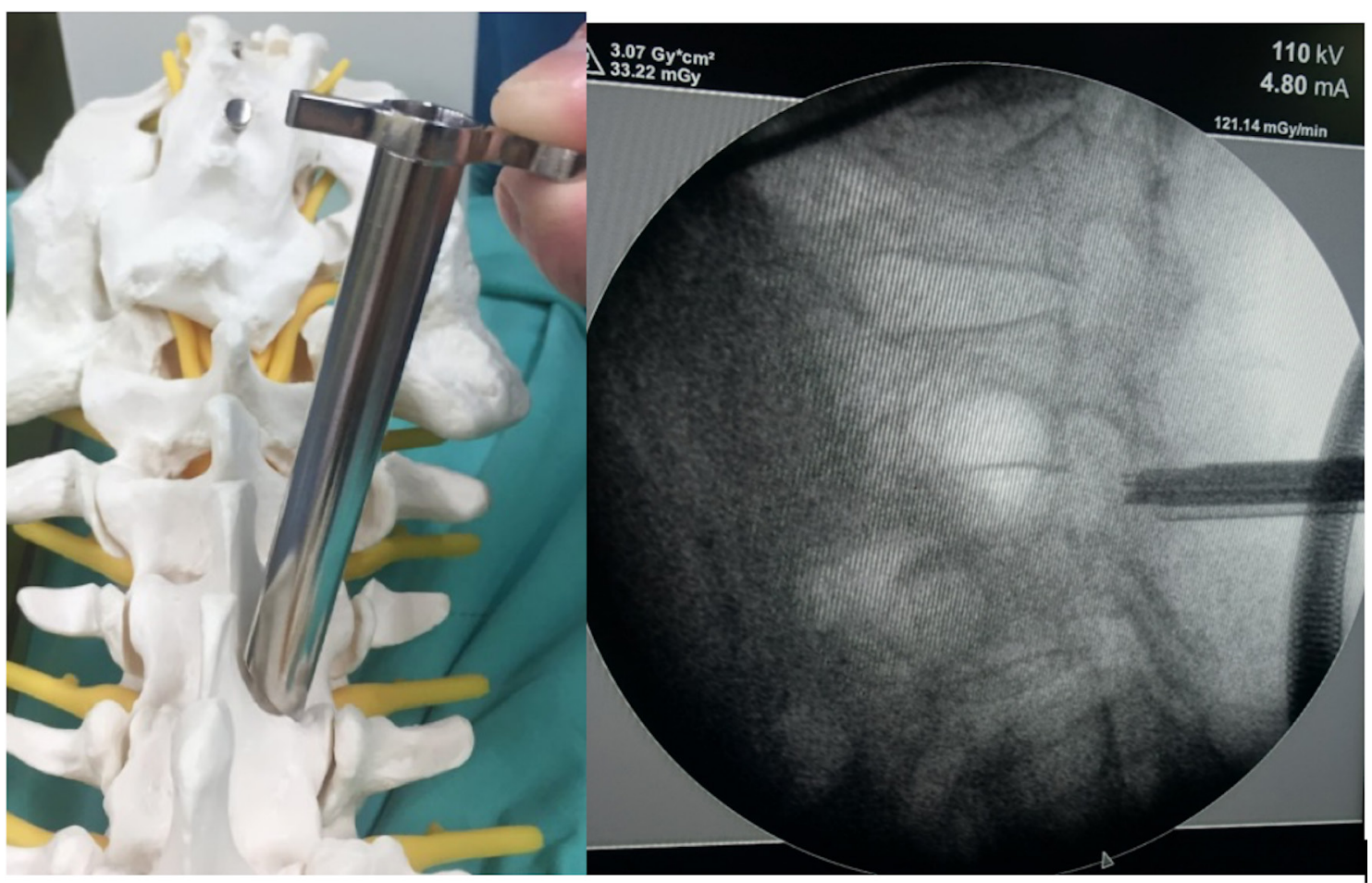

Figure 1. Position and initial identification of the interlaminar window under $\mathrm{C}$-arm.

\section{SURGICAL TECHNIQUES}

The patient is placed in a prone position under general or epidural anesthesia with sedation. First, the surgeon makes a paramedian skin incision of approximately $10 \mathrm{~mm}$ in length (target point: the caudal margin of the upper lamina), then serial dilators are bluntly inserted toward the target point (Figure 1). Next, an operative sheath is inserted over the dilator with the beveled opening facing medially toward the LF. This example of the procedure is performed using the LUSTA endoscopic System (Spinendos, Germany) of a 7.1-mm working channel with a $10^{\circ}$ view angle (Figure 2). Depending on the pathology, ipsilateral decompression, including cranial, caudal laminotomy, and partial medial facetectomy, is performed with endoscopic drills (SPINENDOS GmbH, Munich, Germany), angle adjustable curettes, forceps, and punches. For an ideal ipsilateral decompression, "over the top" pattern decompression is performed by detaching the proximal end of the LF from the caudal border of the upper-level lamina and the distal end of the LF from the cranial edge of the lower-level lamina. Removal of the medial aspect of the facet joint contributed to lateral recess neural compression is also achieved (Figure 3 ).

For bilateral decompression, decompression of the contralateral side is needed after the ipsilateral decompression (Figure 3). The endoscope and the working cannula are conducted toward the contralateral side, entered dorsally to the sublaminar space. At this point, the LF remains intact as far as possible to protect the dural sac. Contralateral bony decompression is performed again by using cranial and caudal laminotomy and partial facetectomy (Figures 4 and 5). If contralateral discectomy is needed, using "channel-in-channel" technique could have better access for less nerve retraction to the contralateral side with a $4.3-\mathrm{mm}$ working channel endoscopy and sheath in a $7.1 \mathrm{~mm}$-large endoscope sheath (Figure 6). ${ }^{25}$ Subsequently, the LF is detached from the drilled bony margin using dissectors and removed with forceps in an en bloc pattern. The decompression is finished when the dura and spinal nerves are noted to be decompressed on both sides. All operation fields were worked under endoscopic visual control and constant saline irrigation.

Before drawing out the endoscope, hydrostatic pressure by adequate irrigation of fluid was used to check the dural sac inflation and check for bleeding points. Sufficient dural expansion is confirmed and bleeding points are controlled with a radiofrequency probe (SPINENDOS $\mathrm{GmbH}$ ) and hemostatic matrix (FLOSEAL). Closed drainage catheter is not necessary in this decompression technique as all bleeding points are double checked and managed with appropriate hemostasis. The incision is then closed with a sterile suture. ${ }^{26}$ 


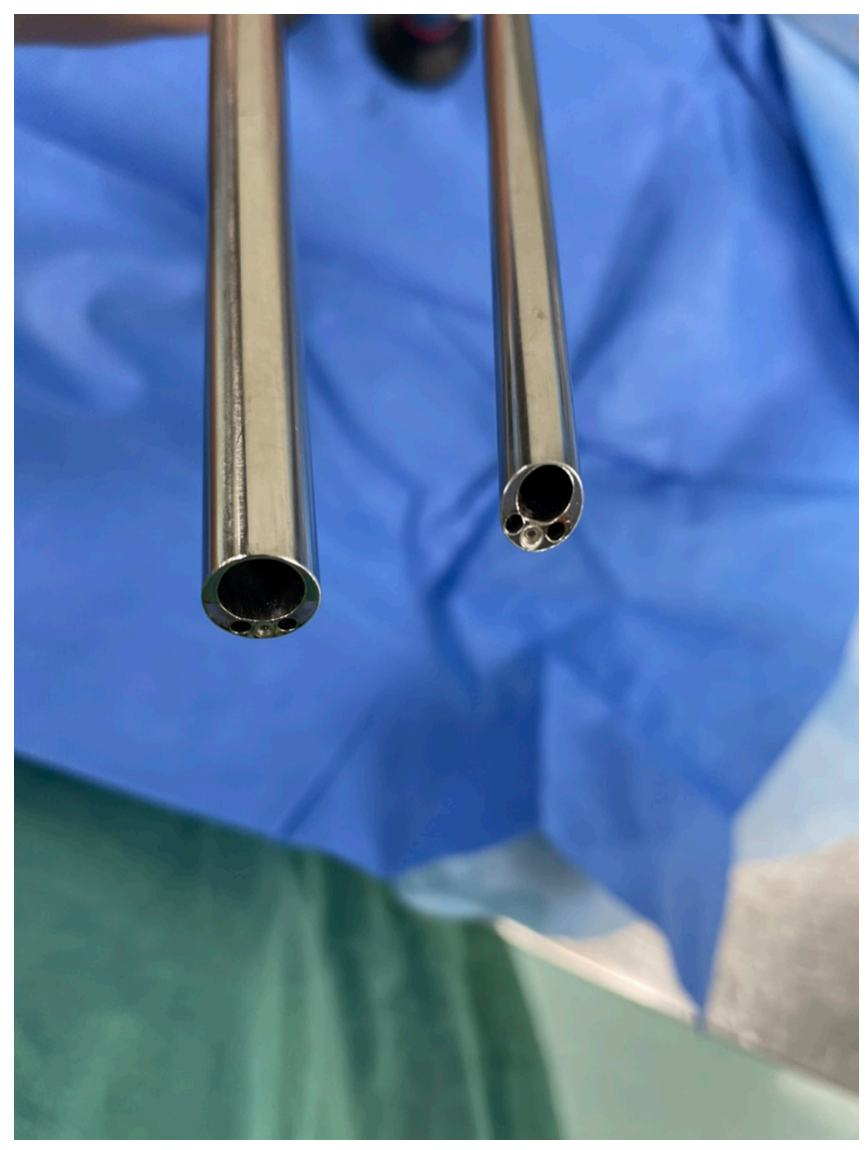

Figure 2. LUSTA endoscopic System (Spinendos, Germany) of 7.1-mm working channel with a $10^{\circ}$ view angle (left) and 4.3-mm working channel with a $25^{\circ}$ view angle (right), respectively.

\section{OUTCOMES}

Since the late 1990s, the number of studies on the possibility and success of minimally invasive endoscopic procedures for a variety of lumbar spinal diseases has increased (Table). A large-scale prospective study of patients receiving lumbar spine surgery via full-endoscopic interlaminar access was published by Ruetten et $\mathrm{al}^{27}$ who reviewed 423 patients who underwent operations in the full-endoscopic technique with interlaminar access between 2001 and 2002. The authors reported that $82 \%$ of the patients no longer had leg pain and $13 \%$ had only occasional pain, with no significant operation-related deterioration in leg or back pain. Neurological deficits were significantly improved within 6 days in all 6 patients with cauda equina syndrome, achieving complete regression of their bladderrectal deficits. There were no measured blood loss or serious complications (postoperative bleeding, injury to dura or nerves), which was favorable compared with conventional surgical approaches. Among all 331 patients, $91 \%$ reported subjective satisfaction and would undergo the procedure again.
In 2009, Ruetten et $\mathrm{al}^{28}$ also published a prospective randomized controlled study comparing the fullendoscopic interlaminar approach versus conventional microscopic technique for lumbar lateral recess stenosis. This study enrolled 192 patients who had symptomatic degenerative lateral recess stenosis between 2003 and 2005, and they were randomized to receive either endoscopic or microscopic decompression surgical technique. The result of this trial demonstrated that the group receiving the full-endoscopic interlaminar approach not only had a $29 \%$ shorter operative duration but also had a relatively low perioperative complication of $1.2 \%$, significantly reduced postoperative pain (VAS) over 5 days, and less use of pain medications. Between the 2 groups, there were equal improvements from baseline in terms of VAS score of leg pain, Oswestry Disability Index (ODI) for low-back pain score, North American Spine Society (NASS) index score, and neurological deficits at the 24-month postoperative follow-up time point.

Multiple retrospective studies comparing endoscopic and microscopic decompression surgery $1,19,20,24,29,30$ showed results of less increase in serum CPK enzyme and significantly shorter hospitalization duration. In addition, the endoscopic group was reported to have a lower increment of horizontal displacement measured. In recent years, more studies with similar results echoed previous publications, showing full-endoscopic decompression is not inferior to previous standardized surgical techniques and even expanded to a wider variety of degenerative spinal diseases with spondylolisthesis and scoliosis.

To build on these initial data demonstrating the success of uniportal endoscopic decompression, there have been a few cohort studies comparing outcomes between uniportal endoscopic decompression, biportal endoscopic decompression, and microscopic decompression techniques. In 2019, Heo et $\mathrm{al}^{31}$ published a comparative analysis of 97 patients (33 in the microscopic group, 37 in the biportal endoscopic group, and 27 in the uniportal endoscopic group). The result of this trial demonstrated that the uniportal endoscopic group had a significantly lower mean dural expansion of $260.77 \mathrm{~mm}^{2}$ and a lower VAS score in the immediate postoperative period. This means the surgeryrelated posterior musculoligamentous damage may be lower in endoscopic technique, allowing early recovery and fewer complications. A systemic review and meta-analysis in $2019,{ }^{21}$ which enrolled 994 patients concluded full-endoscopic had statistically significant lower VAS scores for back pain and lower leg pain 

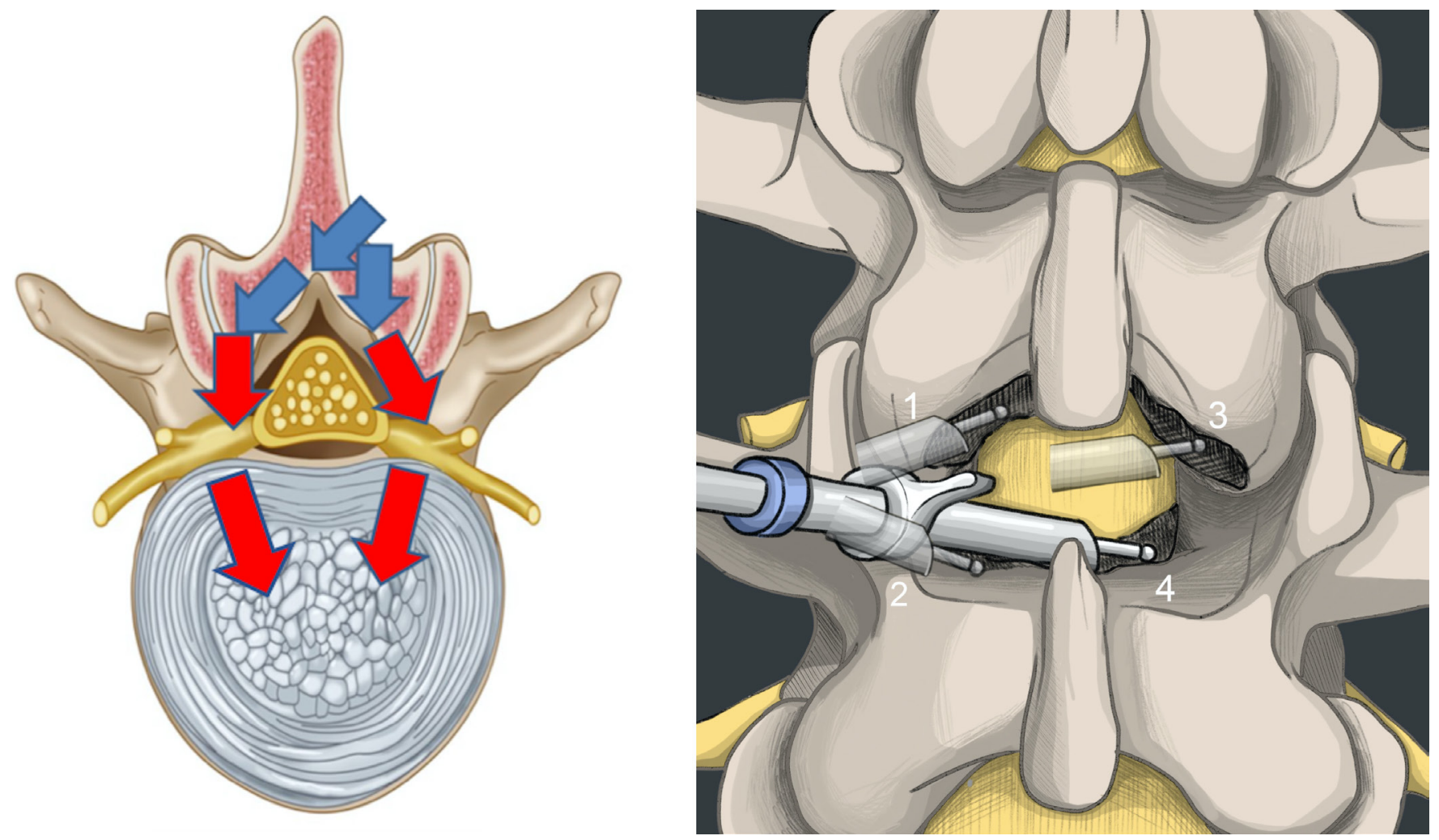

Figure 3. Illustration of the route of endoscopic system insertion for lumbar endoscopic unilateral laminotomy and bilateral decompression (LE-ULBD). (Left) Coronal-section view: The blue arrow indicates 7.1-mm working channel and the red arrow indicates 4.3-mm working channel for ipsilateral and contralateral side decompression in LE-ULBD. (Right) Anteroposterior view: Steps of LE-ULBD by performing (1) ipsilateral cephalad laminotomy, (2) ipsilateral caudal laminotomy, (3) contralateral cephalad laminotomy, and (4) contralateral caudal laminotomy.

VAS, as well as a $40 \%$ lower chance of having complications when compared to microscopic decompression in lumbar stenosis. Of note, there was no difference in ODI and operative time between both groups.

Overall, the literature on uniportal endoscopic lumbar decompression continues to grow, and these series of reviews have illustrated the benefits and satisfactory clinical outcomes that can be had with fullendoscopic decompression techniques compared with the conventional microscopic approach, suggesting a high potential of applications in the future.

\section{ADVERSE EVENTS}

Although full-endoscopic decompression has remarkable advantages in many aspects, there are also some possible disadvantages reported in previous studies. Iatrogenic dural tear is a common complication in endoscopic spinal surgery, mostly occurring in a surgeon's early stage of the learning curve, ${ }^{32}$ as the dural sac can be damaged by highspeed drills and punches in a narrow operative field. ${ }^{33,34}$ Patch-blocking dural repair using collagen

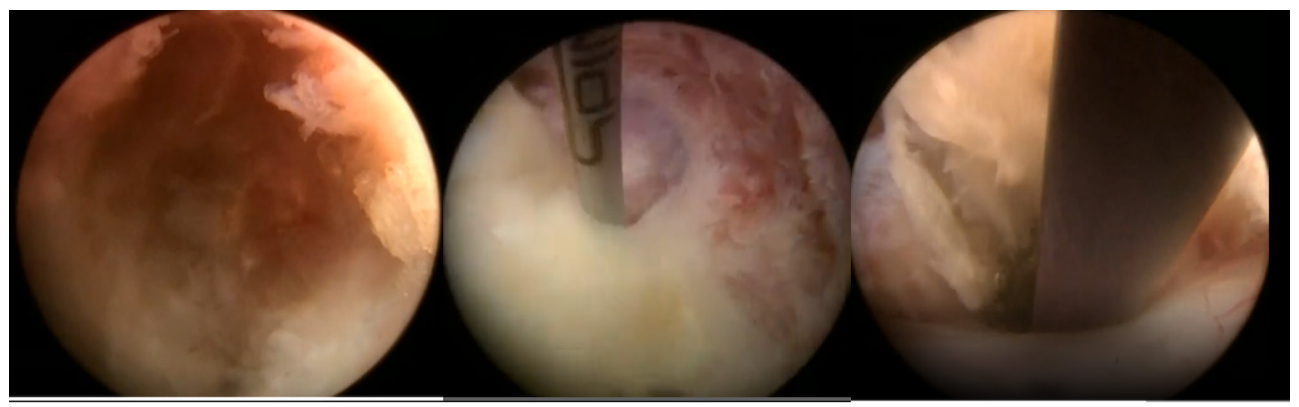

Figure 4. Illustration of endoscopic procedures in lumbar endoscopic unilateral laminotomy for bilateral decompression. (Left) Initial identification of spinolaminar junction. (Middle) Attachment site of ligamentum flavum on the caudal lamina. (Right) Contralateral decompression. 


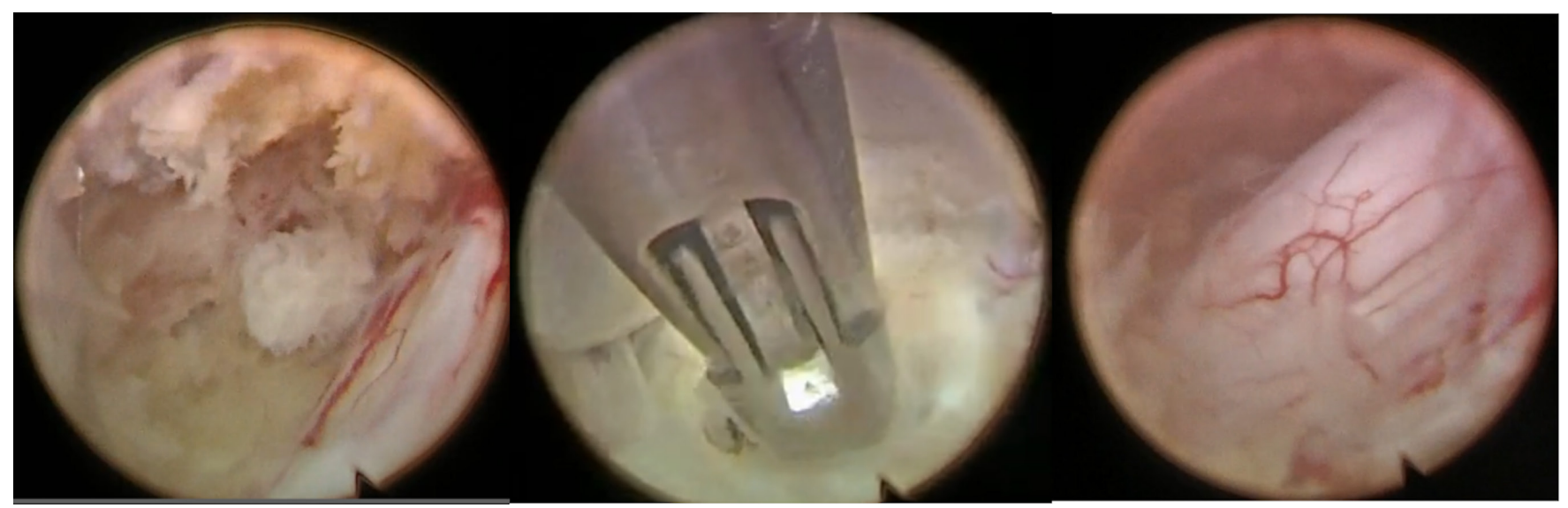

Figure 5. Illustration of procedures during the unilateral endoscopic laminotomy with bilateral decompression. (Left) Exposure of the dural sac. (Middle) Insertion of working sheath for contralateral decompression. (Right) Well decompression of the dural sac.

fibrin patches could resolve this complication, ${ }^{35}$ but if the dural hole is large and dural hole packing fails or unstoppable bleeding points are noted, conversion to open microscopic surgery is necessary. However, owing to the strict patient selection, the chances of large dural tears that require conversion to open surgery are relatively low.

Other common perioperative complications such as epidural hematoma, postoperative dysesthesia, soft tissue, and surgical site infection may be noted but with a relatively low rate. All of these adverse events could be markedly resolved over intensive training of surgeons and cumulative surgical experience. Overall, the incidence of complications was relatively low when compared with conventional decompression techniques. ${ }^{36-41}$

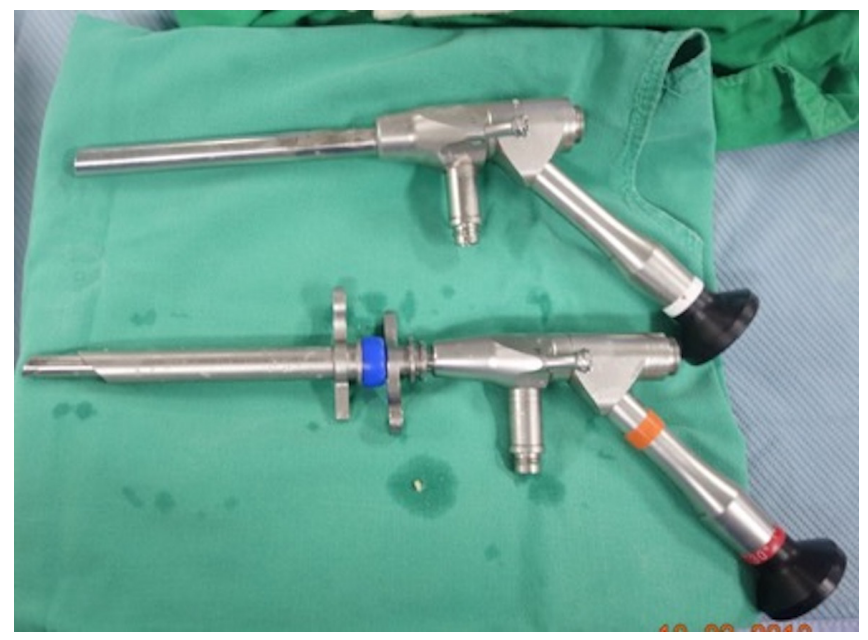

Figure 6. A 4.3-mm working channel endoscopy and sheath using "channelin-channel" technique in a 7.1-mm endoscopic sheath when performing bilateral decompression.

\section{TECHNICAL TIPS}

Methods exist to prevent intraoperative dura damage, which often occurs while surgeons perform LF resection. The key is that surgeons should distinguish the dural sac, traversing nerve root, and exiting nerve root during tissue dissection carefully by keeping the endoscopic view clear in the obscure area. ${ }^{19}$ To reduce trauma and prevent misresection of structures in the blind spot, surgeons should always maintain a clear view by rotating and tilting the endoscope before using endoscopic drills and punches. ${ }^{26}$ Constant saline infusion to the target area may provide a larger epidural working space between the neural structures and the surrounding soft tissues. Starting from the less stenotic side with a full detachment of the LF from the cranial end is more convenient because this may result in more irrigation of fluid flowing into the epidural space, giving aid to a safer neural dissection and minimizing the potential risk of dural tear or nerve root injuries in the more stenotic area. In the case of intraoperative bleeding, the use of high-water pressure, bipolar coagulator, and hemostatic agents ${ }^{42}$ could provide adequate hemostasis.

\section{LEARNING CURVE}

Most minimally invasive techniques have steep learning curves and need longer operative time in the early stage. ${ }^{43,44}$ The full-endoscopic decompression technique has a narrow vision and a small diameter of working space inside the cannula. These limitations resulted in longer operative duration and complications for beginner surgeons who are not familiar with the technique yet. Nevertheless, an 


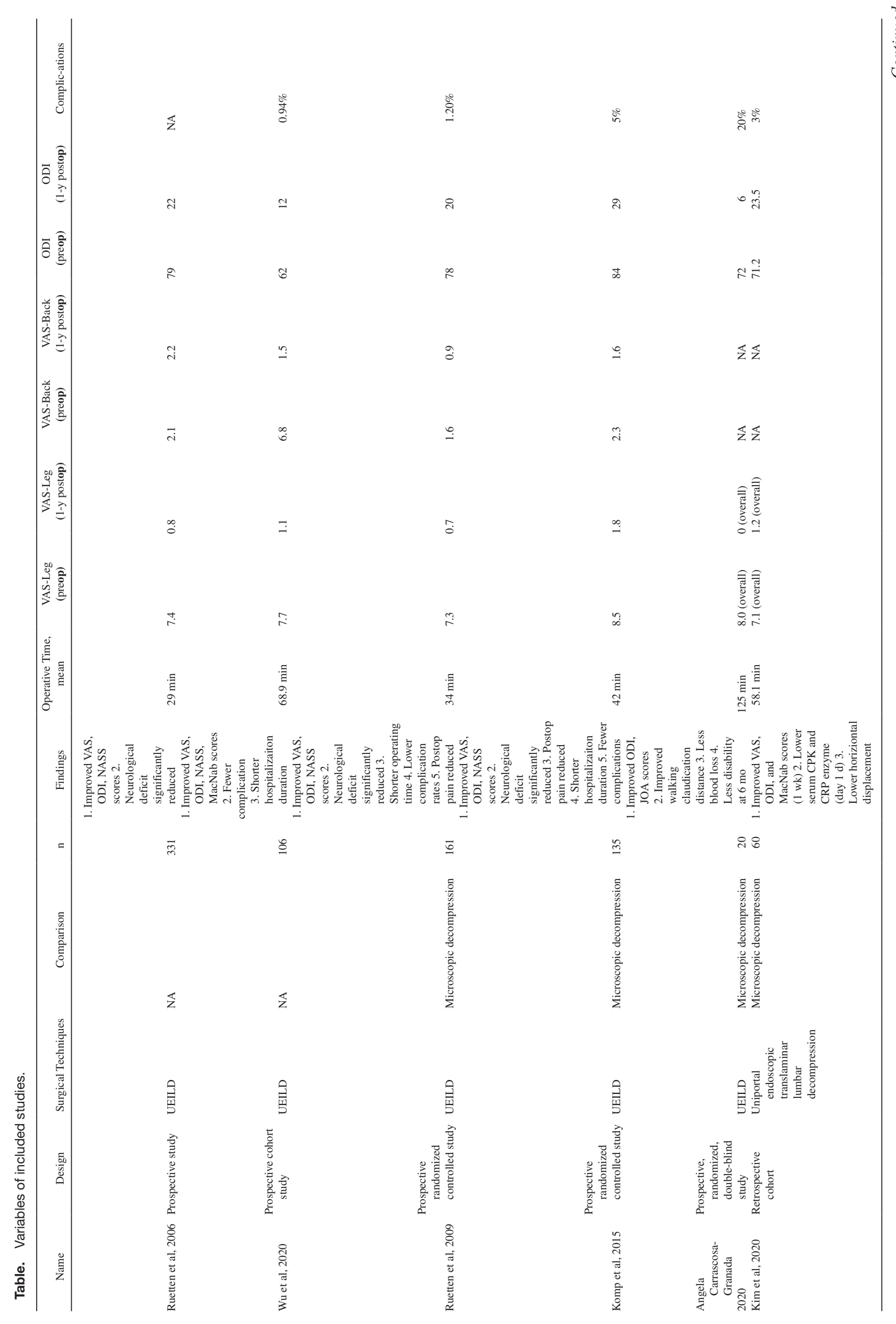


Goh et al.

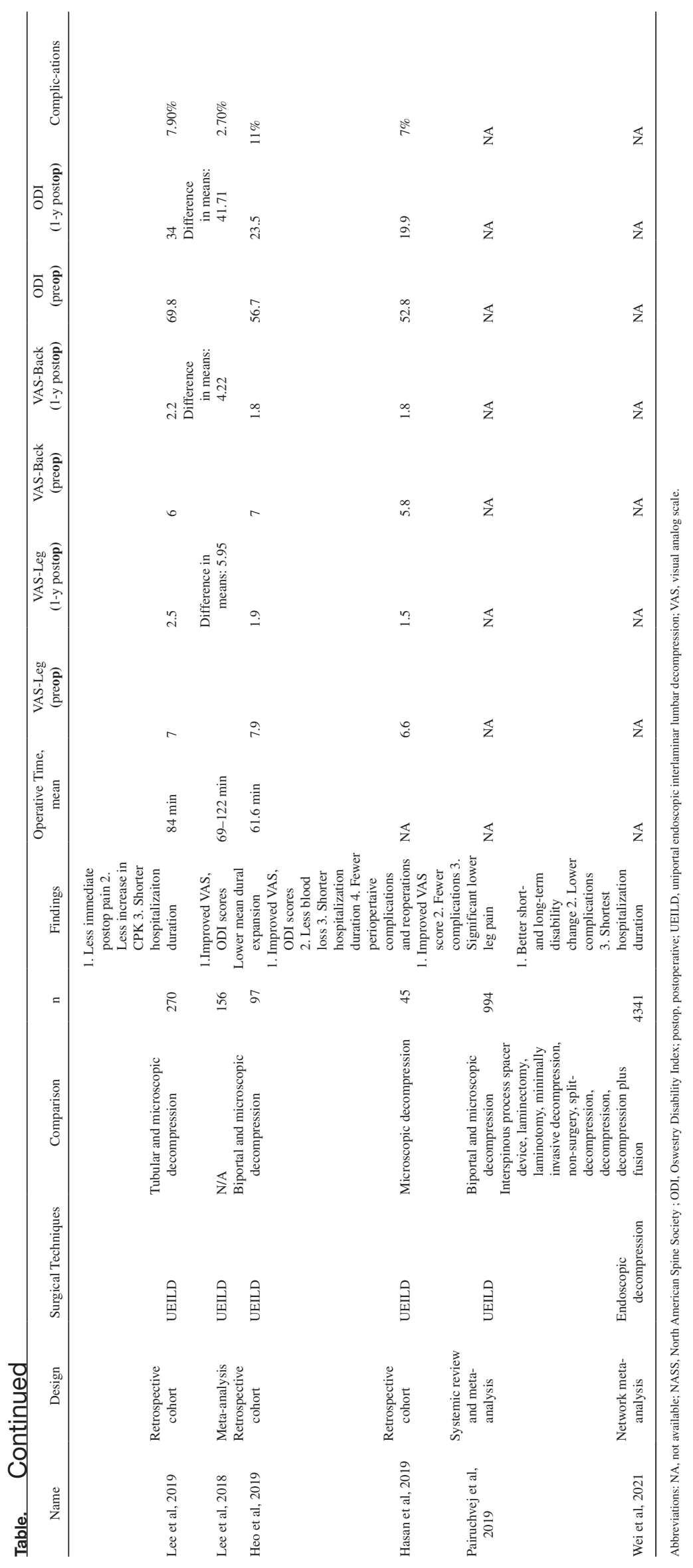


original article composed by Lee et $\mathrm{al}^{32}$ in 2019 suggests that operative time, complication rates, dural sac expansion, and the rate of compression was statistically improved after the 100th case, showing that the clinical outcomes are closely related to the learning curve and proficient of the surgeon.

Interestingly, such a steep learning curve did not affect the postoperative clinical outcomes, and results of full-endoscopic decompression still showed satisfactory clinical outcomes even in the early stages of the learning curve.

\section{FUTURE DIRECTIONS}

The ability to make a quick recovery from surgery while maintaining a high quality of postoperative lifestyle is making the minimally invasive or endoscopic surgery the mainstream of treatments. Additionally, the aging society and the rapid growth of elderly patients with spinal symptoms will increase the demand for endoscopic surgery, as evidence shows that the operations resulted in minimal incisions with shorter hospitalization duration. It is possible that endoscopic surgery could be clinically applied in a broader spectrum of diseases such as infections, tumors, and trauma with further technical developments and research in the near future.

More and more studies recently discussing the current innovation in spine surgery, such as using visual and augmented reality in teaching and preparatory roles, or utilizing surgical settings. Rapid adoption and interpretation of improvements in imaging modalities may make significant differences in patient management and outcomes. Three-dimensional printing could be used for presurgical planning, patient, and trainee communication and education, and even screw drill guides in spinal deformities. Artificial intelligence and robotic-assisted surgery have the potential to reduce surgeon fatigue and improve technical precision. Through the developments in these areas, endoscopic surgery is expected to become the prefered approach in most degenerative spine diseases in the foreseeable future.

\section{CONCLUSIONS}

The techniques of full-endoscopic interlaminar decompression for lumbar spinal stenosis is an emerging technique in the field of minimally invasive surgery. This technique offers numerous advantages, such as relatively better clinical outcomes, minimal tissue trauma, cost-effective procedures because of low postoperative costs of care, and low complication rates. Higher qualities and larger prospective randomized controlled studies are needed to prove the effectiveness and benefits of endoscopic interlaminar lumbar decompression in spinal disease in the future.

\section{REFERENCES}

1. Hasan S, McGrath LB, Sen RD, Barber JK, Hofstetter CP. Comparison of full-endoscopic and minimally invasive decompression for lumbar spinal stenosis in the setting of degenerative scoliosis and spondylolisthesis. Neurosurg Focus. 2019;46(5):E16. doi:10.3171/2019.2.FOCUS195.

2. Amundsen T, Weber H, Nordal HJ, Magnaes B, Abdelnoor M, Lilleâs F. Lumbar spinal stenosis: conservative or surgical management? A prospective 10-year study. Spine. 2000;25(11):1424-1435. doi:10.1097/00007632-200006010-00016.

3. Malmivaara A, Slätis P, Heliövaara M, et al. Surgical or nonoperative treatment for lumbar spinal stenosis? A randomized controlled trial. Spine. 2007;32(1):1-8. doi:10.1097/01.brs. 0000251014.81875.6d.

4. Weinstein JN, Tosteson TD, Lurie JD, et al. Surgical versus nonsurgical therapy for lumbar spinal stenosis. $N$ Engl J Med. 2008;358(8):794-810. doi:10.1056/NEJMoa0707136.

5. Kim HS, Wu PH, Jang I-. T. Current and future of endoscopic spine surgery: what are the common procedures we have now and what lies ahead? World Neurosurg X. 2020;140:642-653. doi:10.1016/j.wneu.2020.03.111.

6. Kambin P, Gellman H. Percutaneous lateral discectomy of the lumbar spine. Clin Orthop Relat Res. 1983;174:127. doi:10.1097/00003086-198304000-00017.

7. Bonaldi G, Belloni G, Prosetti D, Moschini L. Percutaneous discectomy using Onik's method: 3 years' experience. Neuroradiology. 1991;33(6):516-519. doi:10.1007/BF00588044.

8. Mayer HM. Principles of microsurgical discectomy in lumbar disc heriples of Microsurgical Discectomy in Lumbar Disc Herniations. In: Minimally Invasive Spine Surgery: A Surgical Maally. Springer; 2000:73-77. doi:10.1007/978-3-662-08780-0.

9. Caspar W. A new surgical procedure for lumbar disc herniation causing less tissue damage through a microsurgical apnew surgical procedure for lumbar disc herniation causing less tissue damage through a microsurgical approach. Springer; 1977:74-80.

10. Goald HJ. Microlumbar discectomy: follow-up of 477 patients. J Microsurg. 1980;2(2):95-100. doi:10.1002/ micr.1920020204.

11. Telfeian AE, Veeravagu A, Oyelese AA, Gokaslan ZL. A brief history of endoscopic spine surgery. FOC. 2016;40(2):E2. doi:10.3171/2015.11.FOCUS15429.

12. Kambin P, Zhou L. History and current status of percutaneous arthroscopic disc surgery. Spine. 1996;21(24 Suppl):57S-61S doi:10.1097/00007632-199612151-00006.

13. Kambin P, Casey K, O’Brien E, Zhou L. Transforaminal arthroscopic decompression of lateral recess stenosis. J Neurosurg. 1996;84(3):462-467. doi:10.3171/jns.1996.84.3.0462.

14. Xie P, Feng F, Chen Z, et al. Percutaneous transforaminal full endoscopic decompression for the treatment of lumbar spinal stenosis. BMC Musculoskelet Disord. 2020;21(1):546):546-546: doi:10.1186/s12891-020-03566-x. 
15. Destandau J. A special device for endoscopic surgery of lumbar disc herniation. Neurol Res. 1999;21(1):39-42. doi:10.108 0/01616412.1999.11740889.

16. Brayda-Bruno M, Cinnella P. Posterior endoscopic discectomy (and other procedures). Eur Spine $J$. 2000;9 Suppl 1(Suppl 1):S24-9. doi:10.1007/p100010018.

17. Wu C, Lee CY, Chen SC, Hsu SK, Wu MH. Functional outcomes of full-endoscopic spine surgery for high-grade migrated lumbar disc herniation: a prospective registry-based cohort study with more than 5 years of follow-up. BMC Musculoskelet Disord. 2021;22(1):58. doi:10.1186/s12891-020-03891-1.

18. Lee C-H, Choi M, Ryu DS, et al. Efficacy and safety of full-endoscopic decompression via interlaminar approach for central or lateral recess spinal stenosis of the lumbar spine. Spine. 2018;43(24):1756-1764. doi:10.1097/BRS.0000000000002708.

19. Wu M-H, Wu P-C, Lee C-. Y, et al. Outcome analysis of lumbar endoscopic unilateral laminotomy for bilateral decompression in patients with degenerative lumbar central canal stenosis. Spine J. 2021;21(1):122-133. doi:10.1016/j.spinee.2020.08.010.

20. Kim HS, Choi SH, Shim DM, Lee IS, Oh YK, Woo YH. Advantages of new endoscopic Unilateral Laminectomy for Bilateral Decompression (ULBD) over conventional microscopic ULBD. Clin Orthop Surg. 2020;12(3):330-336. doi:10.4055/cios19136.

21. Pairuchvej S, Muljadi JA, Ho JC, Arirachakaran A, Kongtharvonskul J. Full-endoscopic (bi-portal or uni-portal) versus microscopic lumbar decompression laminectomy in patients with spinal stenosis: systematic review and meta-analysis. Eur J Orthop Surg Traumatol. 2020;30(4):595-611. doi:10.1007/s00590-01902604-2.

22. Oichi T, Oshima Y, Chikuda H, et al. In-hospital complication rate following microendoscopic versus open lumbar laminectomy: a propensity score-matched analysis. Spine $J$. 2018;18(10):1815-1821. doi:10.1016/j.spinee.2018.03.010.

23. Wagner R, Haefner M. Indications and contraindications of full-endoscopic interlaminar lumbar decompression. World Neurosurg. 2021;145:657-662. doi:10.1016/j.wneu.2020.08.042.

24. Komp M, Hahn P, Oezdemir S, et al. Bilateral spinal decompression of lumbar central stenosis with the full-endoscopic interlaminar versus microsurgical laminotomy technique: a prospective, randomized, controlled study. Pain Physician. 2015;18(1):61-70.

25. Cao S, Cui H, Lu Z, et al. "Tube in tube" interlaminar endoscopic decompression for the treatment of lumbar spinal stenosis: technique notes and preliminary clinical outcomes of case series. Medicine (Baltimore). 2019;98:e17021. doi:10.1097/ md.0000000000017021.

26. Chen KT, Tseng C, Sun LW, Chang KS, Chen CM. Technical considerations of interlaminar approach for lumbar disc herniation. World Neurosurg. 2021;145:612-620. doi:10.1016/j. wneu.2020.06.211.

27. Ruetten S, Komp M, Godolias G. A New full-endoscopic technique for the interlaminar operation of lumbar disc herniations using 6-mm endoscopes: prospective 2-year results of 331 patients. Minim Invasive Neurosurg. 2006;49(2):80-87. doi:10.1055/s-2006-932172.

28. Ruetten S, Komp M, Merk H, Godolias G. Surgical treatment for lumbar lateral recess stenosis with the full-endoscopic interlaminar approach versus conventional microsurgical technique: a prospective, randomized, controlled study. J Neurosurg Spine. 2009;10(5):476-485. doi:10.3171/2008.7.17634.

29. Lee CW, Yoon KJ, Ha SS. Comparative analysis between three different lumbar decompression techniques (microscopic, tubular, and endoscopic) in lumbar canal and lateral recess stenosis: preliminary report. Biomed Res Int. 2019;2019:6078469. doi:10.1155/2019/6078469.

30. Wei F-. L, Zhou C-. P, Liu R, et al. Management for lumbar spinal stenosis: a network meta-analysis and systematic review. Int J Surg. 2021;85:19-28. doi:10.1016/j.ijsu.2020.11.014.

31. Heo DH, Lee DC, Park CK. Comparative analysis of three types of minimally invasive decompressive surgery for lumbar central stenosis: biportal endoscopy, uniportal endoscopy, and microsurgery. Neurosurg Focus. 2019;46(5):E9. doi:10.3171/2019.2.FOCUS197.

32. Lee CW, Yoon KJ, Kim SW. Percutaneous endoscopic decompression in lumbar canal and lateral recess stenosis - the surgical learning curve. Neurospine. 2019;16(1):63-71. doi:10.14245/ ns.1938048.024.

33. Ahn Y, Lee HY, Lee SH, Lee JH. Dural tears in percutaneous endoscopic lumbar discectomy. Eur Spine J. 2011;20(1):58-64. doi:10.1007/s00586-010-1493-8.

34. Kamenova M, Leu S, Mariani L, Schaeren S, Soleman J. Management of incidental dural tear during lumbar spine surgery. to suture or not to suture? World Neurosurgery. 2016;87:455-462. doi:10.1016/j.wneu.2015.11.045.

35. Kim HS, Raorane HD, PH W, Heo DH, Sharma SB, Jang IT. Incidental durotomy during endoscopic stenosis lumbar decompression: incidence, classification, and proposed management strategies. World Neurosurg. 2020;139:e13-e22. doi:10.1016/j. wneu.2020.01.242.

36. Oertel MF, Ryang YM, Korinth MC, Gilsbach JM, Rohde V. Long-term results of microsurgical treatment of lumbar spinal stenosis by unilateral laminotomy for bilateral decompression. Neurosurgery. 2006;59(6):1264-1270. doi:10.1227/01. NEU.0000245616.32226.58.

37. Podichetty VK, Spears J, Isaacs RE, Booher J, Biscup RS. Complications associated with minimally invasive decompression for lumbar spinal stenosis. J Spinal Disord Tech. 2006;19(3):161-166. doi:10.1097/01.bsd.0000188663.46391.73.

38. Arai Y, Hirai T, Yoshii T, et al. A prospective comparative study of 2 minimally invasive decompression procedures for lumbar spinal canal stenosis: unilateral laminotomy for bilateral decompression (ULBD) versus muscle-preserving interlaminar decompression (MILD). Spine. 2014;39(4):332-340. doi:10.1097/ BRS.0000000000000136.

39. Lee CW, Yoon KJ, Jun JH. Percutaneous endoscopic laminotomy with flavectomy by uniportal, unilateral approach for the lumbar canal or lateral recess stenosis. World Neurosurg. 2018;113:e129-e137. doi:10.1016/j.wneu.2018.01.195.

40. Ahn Y, Kim JU, Lee BH, et al. Postoperative retroperitoneal hematoma following transforaminal percutaneous endoscopic lumbar discectomy. J Neurosurg Spine. 2009;10(6):595-602. doi:10 .3171/2009.2.SPINE08227.

41. Kim HS, Ju CI, Kim SW, Kim JG. Huge psoas muscle hematoma due to lumbar segmental vessel injury following percutaneous endoscopic lumbar discectomy. J Korean Neurosurg Soc. 2009;45(3):192-195. doi:10.3340/jkns.2009.45.3.192.

42. Ahn Y. Current techniques of endoscopic decompression in spine surgery. Ann Transl Med. 2019;7(Suppl 5):S169. doi:10.21037/atm.2019.07.98.

43. Lee DY, Lee SH. Learning curve for percutaneous endoscopic lumbar discectomy. Neurol Med Chir(Tokyo). 2008;48(9):383-389. doi:10.2176/nmc.48.383. 
44. Hsu HT, Chang SJ, Yang SS, Chai CL. Learning curve of fullendoscopic lumbar discectomy. Eur Spine J. 2013;22(4):727-733. doi:10.1007/s00586-012-2540-4.

Funding: The author(s) received no financial support for the research, authorship, and/or publication of this article.

Declaration of Conflicting Interests: The authors report no conflicts of interest in this work
Corresponding Author: Chien-Min Chen; 96015@cch.org.twMeng-Huang Wu; maxwutmu@ gmail.com

Published 31 December 2021

This manuscript is generously published free of charge by ISASS, the International Society for the Advancement of Spine Surgery. Copyright $\odot 2021$ ISASS. To see more or order reprints or permissions, see http:// ijssurgery.com. 